Revista de Metalurgia 51(2)

April-June 2015, e045

ISSN-L: 0034-8570

doi: http://dx.doi.org/10.3989/revmetalm.045

\title{
Marine atmospheric corrosion of carbon steels
}

\author{
Manuel Morcillo ${ }^{\bowtie}$, Jenifer Alcántara, Iván Díaz, Belén Chico, Joaquín Simancas, Daniel de la Fuente \\ Centro Nacional de Investigaciones Metalúrgicas (CENIM-CSIC), Avda. Gregorio del Amo 8, 28040 Madrid, España \\ Corresponding author: morcillo@cenim.csic.es
}

Submitted: 6 May 2015; Accepted: 18 May 2015; Available On-line: 23 J une 2015

\begin{abstract}
Basic research on marine atmospheric corrosion of carbon steels is a relatively young scientific field and there continue to be great gaps in this area of knowledge. The presence of akaganeite in the corrosion products that form on steel when it is exposed to marine atmospheres leads to a notable increase in the corrosion rate. This work addresses the following issues: (a) environmental conditions necessary for akaganeite formation; (b) characterisation of akaganeite in the corrosion products formed; (c) corrosion mechanisms of carbon steel in marine atmospheres; (d) exfoliation of rust layers formed in highly aggressive marine atmospheres; (e) long-term corrosion rate prediction; and (f) behaviour of weathering steels. Field research has been carried out at Cabo Vilano wind farm (Camariñas, Galicia) in a wide range of atmospheric salinities and laboratory work involving the use of conventional atmospheric corrosion techniques and near-surface and bulk sensitive analytical techniques: scanning electron microscopy (SEM)/energy dispersive spectrometry (EDS), X-ray diffraction (XRD), Mössbauer spectroscopy and SEM/ $\mu$ Raman spectroscopy.
\end{abstract}

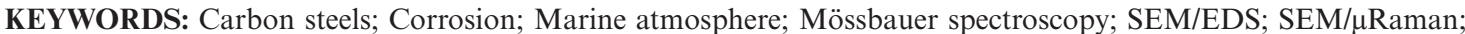
TEM/ED; XRD

Citation / Cómo citar este artículo: Morcillo, M., Alcántara, J., Díaz, I., Chico, B., Simancas, J., de la Fuente, D. (2015) "Marine atmospheric corrosion of carbon steels". Rev. Metal. 51(2): e045. doi: http://dx.doi.org/10.3989/revmetalm.045.

RESUMEN: Corrosión atmosférica marina de aceros al carbono. La investigación fundamental en corrosión atmosférica marina de aceros al carbono es un campo científico relativamente joven que presenta grandes lagunas de conocimiento. La formación de akaganeíta en los productos de corrosión que se forman sobre el acero cuando se expone a atmósferas marinas conduce a un incremento notable de la velocidad de corrosión. En el trabajo se abordan las siguientes cuestiones: (a) condiciones ambientales necesarias para la formación de akaganeíta, (b) caracterización de la akaganeíta en los productos de corrosión formados, (c) mecanismos de corrosión del acero al carbono en atmósferas marinas, (d) exfoliación de las capas de herrumbre formadas en atmósferas marinas muy agresivas, (e) predicción de la velocidad de corrosión a largo plazo, y (f) comportamiento de aceros patinables. La investigación se ha llevado a cabo en campo, en el Parque Eólico de Cabo Vilano (Camariñas, Galicia) en un amplio rango de salinidades atmosféricas, y a nivel de laboratorio acudiendo a técnicas convencionales de corrosión atmosférica y diversas técnicas analíticas de caracterización de superficies: microscopía electrónica de barrido (MEB)/ espectrometría de dispersión de energía (EDE), difracción de rayos-X (DRX), espectroscopía Mössbauer y MEB/espectroscopía $\mu$ Raman.

PALABRAS CLAVE: Acero al carbono; Atmósfera marina; Corrosión; Difracción de rayos X; Espectroscopía Mössbauer; Espectroscopía $\mu$ Raman; Microscopía electrónica de barrido/Espectroscopia de dispersión de energía; Microscopía electrónica de transmisión/Difracción de electrones

Copyright: (C) 2015 CSIC. This is an open-access article distributed under the terms of the Creative Commons Attribution-Non Commercial (by-nc) Spain 3.0 License. 


\section{INTRODUCTION}

\subsection{Fundamental mechanism of carbon steel atmospheric corrosion}

The atmospheric corrosion of metals is an electrochemical process which is the sum of individual processes that take place when an electrolyte layer forms on the metal. This electrolyte can be either an extremely thin moisture film (just a few monolayers) or an aqueous film of hundreds of microns in thickness (when the metal is perceptibly wet). Aqueous precipitation (rain, fog, etc.) and humidity condensation due to temperature changes (dew) are the main promoters of metallic corrosion in the atmosphere.

The magnitude of the corrosion fundamentally depends upon the length of time that the surface is wet, although it is, in fact, a function of a series of factors, such as rain, relative humidity, temperature, exposure conditions, atmospheric pollution, composition of the metal, properties of the formed oxide, etc.

Atmospheric corrosion, as a global process, includes simultaneous oxidation and reduction reactions, which can be accompanied by other chemical reactions, with an eventual participation of the corrosion products.

The anodic reaction, consisting of the oxidation of the metal, can be given as:

$\mathrm{Fe} \rightarrow \mathrm{Fe}^{2+}+2 \mathrm{e}^{-}$

Oxygen which is highly soluble in the aqueous layer is a possible acceptor of electrons. The reduction of oxygen in neutral or basic media takes place according to the reaction:

$\mathrm{O}_{2}+2 \mathrm{H}_{2} \mathrm{O}+4 \mathrm{e}^{-} \rightarrow 4 \mathrm{OH}^{-}$

Only in the case of a high degree of pollution with acid products does the cathodic reaction of a discharge of hydrogen ions becomes of importance

$2 \mathrm{H}^{+}+2 \mathrm{e}^{-} \rightarrow \mathrm{H}_{2}$

Atmospheric corrosion products of iron and its alloys, referred to as "rust", comprise various types of oxides, hydrated oxides, oxyhydroxides and miscellaneous crystalline and amorphous substances that form as a result of the reaction between steel and their environment. Such substances may originate from the substrate itself (endogenous products) or from the atmosphere (exogenous products). Table 1 lists the corrosion products most frequently found in the layers formed on carbon steel exposed to the atmosphere. Hiller (1966) considers lepidocrocite to be primary crystalline corrosion product. In mildly acidic solutions lepidocrocite is transformed into goethite, the most stable of ferric oxyhydroxides.
TABLE 1. Phases commonly found in rust layers

\begin{tabular}{lc}
\hline Name & Mineralogical formula \\
\hline Oxides & \\
Hematite & $\alpha-\mathrm{Fe}_{2} \mathrm{O}_{3}$ \\
Maghemite & $\gamma-\mathrm{Fe}_{2} \mathrm{O}_{3}$ \\
Magnetite & $\mathrm{Fe}_{3} \mathrm{O}_{4}$ \\
Ferrihydrite & $\mathrm{Fe}_{5} \mathrm{HO}_{8} \cdot 4 \mathrm{H}_{2} \mathrm{O}$ \\
Oxyhydroxides & \\
Goethite & $\alpha-\mathrm{FeOOH}$ \\
Akaganeite & $\beta-\mathrm{FeOOH}$ \\
Lepidocrocite & $\gamma-\mathrm{FeOOH}$ \\
Feroxyhite & $\delta-\mathrm{FeOOH}$ \\
\hline
\end{tabular}

Magnetite is another important thought minor rust constituent which is usually detected in the inner part of the rust layer, close to the base steel where the oxygen concentration is depleted. In marine atmospheres, where the surface electrolyte contains chlorides, akaganeite is formed. Other phases (feroxyhyte, maghemite, hematite, ferrihydrite, etc.) have also been found on steel exposed in different types of atmosphere.

Rust layers usually present considerable porosity, spallation and cracking. Cracked and nonprotective oxide layers (open structures) allow the corrosive species easy access to the metallic substrate, and is the typical situation in atmospheres of high aggressivity. In contrast, more compact oxide layers (closed structures) favour the protection of the metallic substrate. The greater the corrosivity of the atmosphere, the easier it is to find very open structures favouring rust film breakdown (detachment, spalling) and the initiation of fresh attack (Morcillo et al., 2011).

In 1973 Barton (1973) noted that the mechanism governing the effects of chloride ions in atmospheric corrosion had not been completely explained, and that the higher corrosion rate of steel in marine atmospheres by the higher conductivity of the aqueous layer where marine aerosol is dissolved, could also be due to other causes: (a) being hygroscopic, chloride species (sodium chloride, calcium chloride or magnesium chloride) promote the electrochemical corrosion process, favouring the formation of electrolytes at relatively low relative humidity $(\mathrm{RH})$ values, and (b) the solubility of the corrosion products formed; thus, in the case of iron, which does not form stable basic chlorides, the action of chlorides is more pronounced than with other metals (zinc, copper, etc.) whose basic salts are only slightly soluble.

Since then, there has been great progress in scientific knowledge of atmospheric corrosion (Morcillo et al., 2014a). However, Nishimura et al. (2000) have pointed out that research on the fundamental mechanisms of rust formation in chloride-rich marine 
atmospheres had been rather scarce. This work sets out the peculiarities and uncertainties related with carbon steel corrosion in marine atmospheres, describes the researches which are being carried out at CENIM in this matter, and highlights some of the questions that still remain unanswered.

\subsection{Atmospheric corrosion of carbon steel in chloride-rich atmospheres. A young scientific field with great knowledge lacks}

It is important to gain a more in-depth knowledge of the corrosion mechanisms of carbon steel in marine atmospheres, where the variable with the greatest influence is undoubtedly the chloride ion deposition rate (atmospheric salinity) at the exposure site (Morcillo et al., 2014b).

In marine atmospheres, the presence of akaganeite phase among the corrosion products is especially significant. In relation with this corrosion product, a number of important questions remain unanswered as will be seen below.

In very severe marine atmospheres occurs the formation of thick rust layers that are exfoliated (detached) from the steel base. The microstructure of that corrosion layers is very unusual (multilaminar rust). There is a lack of basic knowledge on the formation mechanisms and their internal microstructure.

For long-term prediction of carbon steel atmospheric corrosion, data on the evolution of carbon steel corrosion $(\mathrm{C})$ with exposure time $(\mathrm{t})$, the power function $\mathrm{C}=\mathrm{At}^{\mathrm{n}}$ is usually applied. The variables upon which $n$ constant depends are not fully known, though the salinity of the atmosphere undoubtedly must play a prominent role. However, in highly severe marine atmospheres that power function, based on diffusion mechanisms, cannot sometimes be applicable. What growing laws of rust layers formed in these conditions could be applied?

Finally, it is important to know the behaviour of new commercial Weathering Steels (WS) in marine atmospheres; One of the main limitations of conventional WS (e.g. Cor-Ten) is the non-formation of protective rust layers in marine atmospheres (Morcillo et al., 2013). What is the behaviour in these conditions of WS formulated with higher $\mathrm{Ni}$ contents (e.g. Cu- 0.4 wt. \%, Ni- 3 wt. \%) commercially available today? (Nippon Steel Corporation, 2006).

\section{EXPERIMENTAL}

Research has been carried out in the pure marine atmosphere of Cabo Vilano wind farm (Camariñas, Galicia) at corrosion stations located at different distances from the shore. Figure 1 shows the geographic location of the wind farm and the siting of the corrosion stations. Table 2 shows the wide range of chloride ion deposition rates considered; the atmospheric $\mathrm{SO}_{2}$ content was negligible $\left(1.0 \mathrm{mg} \mathrm{SO} / \mathrm{m}^{2}\right.$-day). Frequent heavy rainfall and high relative humidity levels were recorded at the test site, indicating prolonged times of wetness of the metallic surface (Morcillo et al., 2014b).

Three types of carbon steel have been considered in the present research: one mild steel, one conventional weathering steel (Cor-Ten A, ASTM A-242 (2007)), supplied by ThyssenKrupp, and one advanced weathering steel designed specifically for marine atmospheres (2.83 wt. \% Ni, 0.28 wt. \% Cu) and manufactured at the National Centre for Metallurgical Research (CENIM) (Cano, 2013; Díaz, 2012). The compositions of these steels are given in Table 3.

The corrosion stations were affixed using magnets to the north-facing side of wind turbine towers, this being the predominant wind direction at the exposure site according to historic records. Each station consisted of a rack containing a device to measure atmospheric salinity (wet candle) (EN ISO 9225, 2012) at the bottom and carbon steel specimens at the top (Morcillo et al., 2014b).

The attack experienced by the steel as a consequence of its exposure to the atmosphere was determined in triplicate using the mass loss technique, in accordance with Annex A, designation C.3.5 of ISO 8408 standard (1991).

The rust formed on all three exposed materials has been described in detail taking into account aspects such as the formation of rust particles (grains) or flakes and the occurrence of exfoliation (Raman, 1988). Grain size has been determined using the "tape method", which consists of adhering a $2 \times 2 \mathrm{~cm}^{2}$ piece of adhesive tape to the rust layer, pressing firmly and evenly on the surface, and lifting off to examine the size and density of detached rust particles (Hara et al., 2007). Rust samples for analysis were obtained removing by rigorous brushing with a small nylon brush. Then, were ground to a fine powder (particle size $\leq 125 \mu \mathrm{m})$ using an agate mortar and pestle.

The corrosion products have been characterised by X-ray diffraction (XRD). XRD measurements were carried out with a Bruker AXS D8 diffractometer equipped with Co X-ray tube by Goebel mirror optics and a LynxEye Linear Position Sensitive Detector for ultra-fast XRD measurements. A current of $30 \mathrm{~mA}$ and a voltage of $40 \mathrm{kV}$ were employed as tube settings. Operational conditions were selected to obtain XRD profiles of sufficient quality, namely optimal counting statistics, narrow peaks, and the detection of small diffraction peaks of minor phases. XRD data was collected over a $2 \theta$ range of $10-80^{\circ}$ with a step width of $0.017^{\circ}$ and a counting time of 2 s/step. Qualitative identification of crystalline phases present in the rust formed on the steels has been performed from XRD patterns using the JCPDS database and the DIFFRACplus EVA software by Bruker AXS. In some cases $\mu$ XRD measurements were also performed in order to know the composition of the rust throughout the thickness of the 


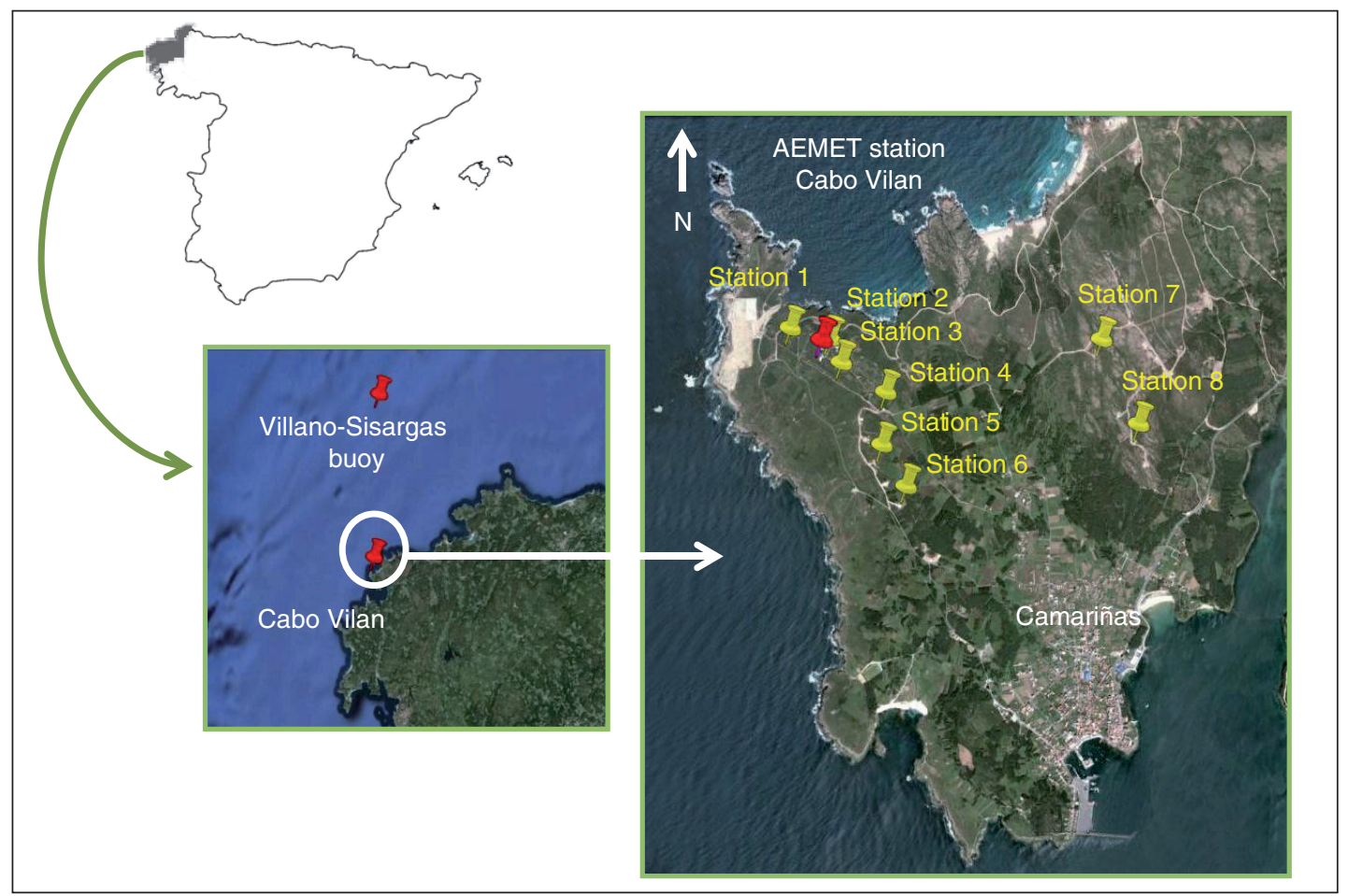

FIGURE 1. Geographic location of the test site and position of the eight corrosion stations. The position of the AEMET weather sttaion (Cabo Vilan) and the State Port Authority buoy (Villano-Sisargas) is also shown.

rust layer. $\mu$ XRD measurements were collected with a Bruker AXS D8 diffractometer equipped with a Co $\mathrm{X}$-ray tube, a primary-beam collimator and a laser that

TABLE 2. Distance between the testing stations and the shore in northerly direction and annual average salinity values

\begin{tabular}{lcc}
\hline $\begin{array}{l}\text { Corrosion station } \\
\text { (see Fig. 1) }\end{array}$ & $\begin{array}{c}\text { Annual average salinity } \\
\left(\mathbf{m g ~ C l} \mathbf{~}^{-} / \mathbf{m}^{\mathbf{2}} \cdot \mathbf{d a y}\right)\end{array}$ & $\begin{array}{c}\text { Distance to } \\
\text { the shore (m) }\end{array}$ \\
\hline Station 1 & $823^{\mathrm{a}}$ & 280 \\
Station 2 & $1906^{\mathrm{a}}$ & 332 \\
Station 3 & 665 & 420 \\
Station 4 & 272 & 590 \\
Station 5 & 206 & 945 \\
Station 6 & 109 & 1250 \\
Station 7 & $92^{\mathrm{b}}$ & 1630 \\
Station 8 & 70 & 2400 \\
\hline
\end{tabular}

${ }^{a, b}$ These values corresponds to the first 6 months (a) and first 9 months (b) of exposure, respectively. focused on the point of the surface to be analysed (500 $\mu \mathrm{m}$ in diameter) and a LynxEye linear detector.

An important XRD limitation is differentiation of iron oxides magnetite and maghemite. The diffractograms for magnetite/maghemite are practically identical (similar crystalline structures) and so their identification by XRD is very complicated when mixed with large amounts of other phases. Both phases are associated to the diffraction angle next to $35^{\circ}$ (Antunes et al., 2003). For the sake of simplicity, both iron oxides are referred to in this paper as "spinel". To differentiate both compounds Mössbauer spectroscopy was used. Mössbauer data was recorded at room temperature and $16 \mathrm{~K}$ using a conventional constant acceleration spectrometer, a He closed-cycle cryogenerator and a ${ }^{57} \mathrm{Co}(\mathrm{Rh})$ source. Absorbers were prepared to have approximately $5-10 \mathrm{mg} \mathrm{Fe} / \mathrm{cm}^{2}$. The velocity scale was calibrated using a $6 \mu \mathrm{m}$-thick natural iron foil. All the spectra were computer-fitted and the isomer shifts were referred to the centroid of the room temperature spectrum of $\alpha-\mathrm{Fe}$.

TABLE 3. Test specimen dimensions and chemical composition of the carbon steels used

\begin{tabular}{|c|c|c|c|c|c|c|c|c|c|c|}
\hline \multirow[b]{2}{*}{ Type of steel } & \multirow[b]{2}{*}{ Designation } & \multirow[b]{2}{*}{ Dimension (mm) } & \multicolumn{8}{|c|}{ Chemical composition (wt. \%) } \\
\hline & & & $\mathrm{C}$ & $\mathbf{S i}$ & Mn & $\mathbf{P}$ & $\mathbf{S}$ & $\mathrm{Cr}$ & $\mathbf{N i}$ & $\mathbf{C u}$ \\
\hline Mild steel & MS & $100 \times 50 \times 1.0$ & 0.13 & 0.09 & 0.55 & 0.02 & 0.018 & 0.12 & 0.02 & 0.02 \\
\hline Conventional WS (ASTM A-242) & CWS & $100 \times 50 \times 1.5$ & 0.08 & 0.40 & 0.42 & 0.10 & 0.018 & 0.48 & 0.18 & 0.42 \\
\hline Advanced WS (2.83 wt. \%, Ni, 0.28 wt. $\% \mathrm{Cu}$ ) & AWS & $50 \times 50 \times 3.3$ & 0.18 & 0.26 & 0.70 & 0.01 & 0.016 & 0.08 & 2.83 & 0.28 \\
\hline
\end{tabular}


Cross-sections of rust layers were also prepared in order to view its microstructure by optical microscopy. Observations were carried out using a Nikon EPIPHOT 300 light microscope coupled to an Infinity 2 camera.

In order to precisely identify the akaganeite crystals formed, a selected area electron diffraction (SAED) and high resolution transmission electron microscopy (HRTEM) were performed on a JEOL 300 FEG electron microscope. The chemical composition in each crystal was determined by energydispersive X-ray spectrometry (EDS) with an Oxford INCA analyser system. The samples were ultrasonically dispersed in n-butanol and then transferred to carbon-coated copper grids.

For scanning electron microscopy (SEM)/EDS studies high resolution SEM was carried out with a Hitachi S4800 and a JEOL JSM-7600F field emission gun scanning electron microscopes working at an acceleration voltage of $2-5 \mathrm{keV}$ at different magnifications. SEM equipments were equipped with secondary electron and backscattered electron detectors. EDS was conducted with an Oxford Inca analyzer system attached to the SEM working at an acceleration voltage of $15 \mathrm{keV}$ to minimise the matrix effects.

When assigning a certain morphology observed by SEM to a particular compound, the results obtained by EDS are not obviously conclusive, since this technique provides information about the chemical elements present and not about the compound involved. For this purpose, use was made of the SEM/ $\mu$ Raman technique. An integrated Raman-SEM microscope consisting of a SEM JEOL 6610 LV and a Hybriscan HSCM M 21 confocal Raman was used. The lateral and axial resolutions of this microscope are approximately 0.5 and $5 \mu \mathrm{m}$ respectively. The Raman module is equipped with a $785 \mathrm{~nm}$ laser as the excitation source. The laser power was adjusted such that approximately $50-100 \mu \mathrm{W}$ of light was delivered on the sample with exposure times of 15 seconds or more and averaging over multiple spectra with a total exposure time ranging from 90 seconds up to 16 minutes. SEM images were obtained with a $650 \mathrm{x}$ magnification, $5 \mathrm{kV}$ acceleration voltage with the backscatter detector.

\section{RESULTS AND DISCUSSION}

\subsection{Environmental conditions for akaganeite formation in marine atmosphere carbon steel corrosion products and its characterisation}

\subsubsection{Environmental conditions for akaganeite formation}

As was pointed out before, the formation of akaganeite leads to a notable acceleration of the steel corrosion process in marine atmospheres. Although the presence of akaganeite has been identified by powder
XRD in numerous studies, it has not been detectable in many other outdoor marine exposure tests, even in atmospheres with relatively high airborne chloride concentrations. A number of important questions in relation with akaganeite remain unanswered: What environmental conditions are necessary for its formation? Is there a critical atmospheric salinity concentration below which it is unlikely to form? Where is it preferentially located in the steel corrosion products layer? (Morcillo et al., 2014b).

In order to determine what environmental conditions of the atmosphere are necessary for the formation of akaganeite, an exhaustive review has been made of tests reported in the literature (Morcillo et al., 2015). Consideration has only been made of studies performed on mild steel which provided information on the annual average $\mathrm{RH}$ of the exposure site, the $\mathrm{Cl}^{-}$ion deposition rate using the wet candle method, the steel corrosion rate in the first year of exposure, and at least qualitative identification of corrosion products by XRD. With the aim of better visualising the environmental conditions of $\mathrm{RH}$ and $\mathrm{Cl}^{-}$deposition rate that lead to the formation of akaganeite, Fig. 2 has been prepared, which displays in log-log coordinates the corrosion rate of mild steel during the first year of atmospheric exposure as a function of the annual average $\mathrm{Cl}^{-}$ion deposition rate at the exposure site. The points on the graph, represented by circles, include an indication of the annual average $\mathrm{RH}$ at the exposure site. Black circles represent test sites where akaganeite had been identified, and white circles represent test sites where it had not been possible to identify this oxyhydroxide by XRD (qualitative).

Figure 2 provides a general indication of the environmental conditions of the atmosphere that lead to the formation of akaganeite: annual average $\mathrm{RH}$ around $80 \%$ or higher and simultaneously an annual average chloride deposition rate of around $60 \mathrm{mg} / \mathrm{m}^{2}$ day or higher. That is, in marine atmospheres of Saudi Arabia (points A in Fig. 2) the low $\mathrm{RH}$ impedes the formation of akaganeite, and therefore leads to low steel corrosion rates, despite the high chloride deposition rates. Something similar happens at some test site in India (point B in Fig. 2). This confirms the laboratory experiments carried out by Rémazeilles and Refait (2007), which indicate that a high chloride concentration is not the only condition for the formation of akaganeite. The medium must be characterised by large dissolved $\mathrm{Fe}^{2+}$ concentrations as well, which occur in the electrolyte films that form on the metallic surface in humid atmospheres (high RH and high time of wetness (TOW)).

These critical conditions, $\mathrm{RH}$ around $80 \%$ or higher and $\left[\mathrm{Cl}^{-}\right]$around of $60 \mathrm{mg} / \mathrm{m}^{2}$.day or higher, must be taken as an approximation to the environmental conditions necessary for the formation of akaganeite. Other specific environmental conditions of the exposure site, such as atmospheric air temperature, annual precipitation volume, duration of 


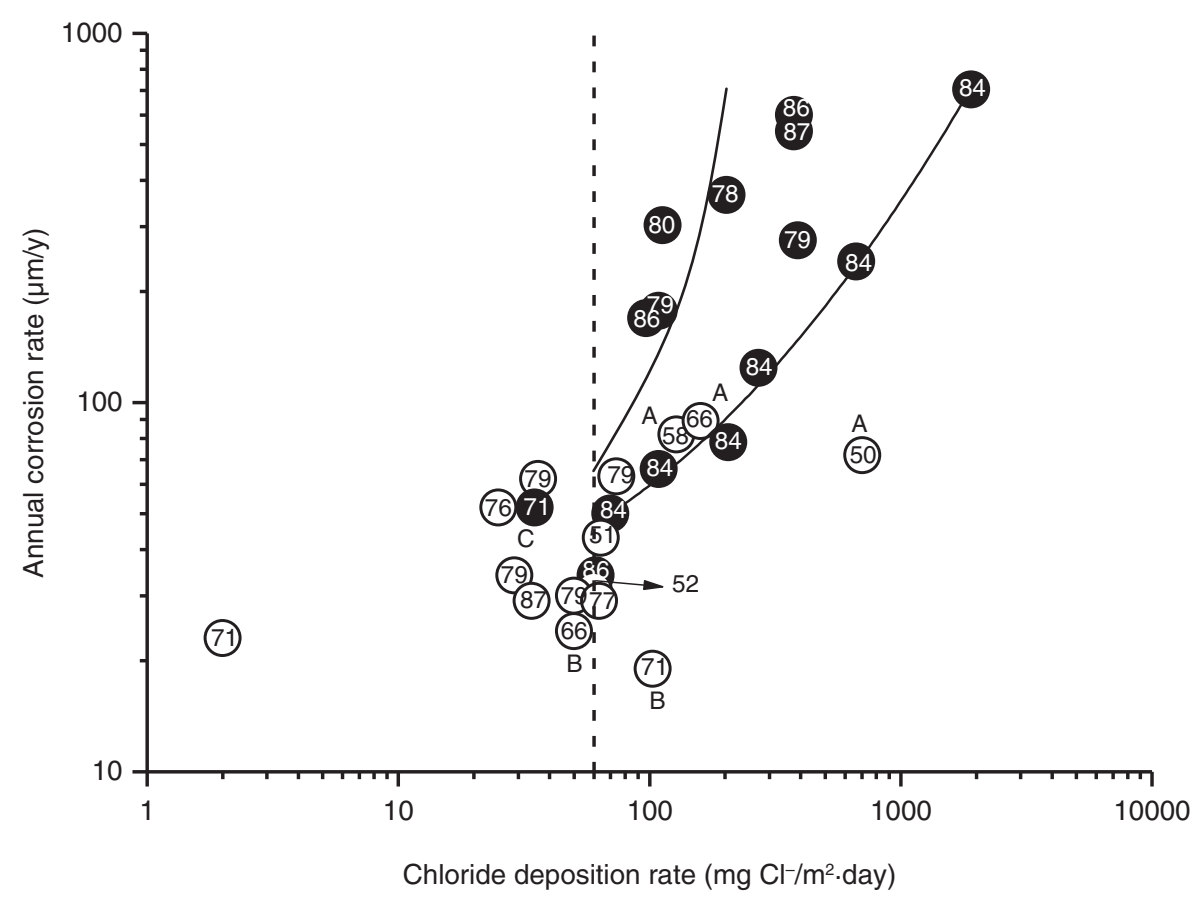

FIgURE 2. Corrosion rate of mild steel during the first year of atmospheric exposure as a function of the annual average chloride deposition rate at the exposure site. The points of the graph, represented by circles, include an indication of the annual average $\mathrm{RH}$ at the exposure site. Black circles represent test sites where akaganeite had been identified, and white circles represent test sites where it had not been possible to identify it by XRD (qualitative).

wet/dry cycles, marine aerosol entrainment regime, etc., may also influence whether or not akaganeite forms in conditions that, while similar, do not fully correspond with the critical conditions established above. This could be the case of formation of akaganeite in atmospheres of Canary Islands (point C in Fig. 2) at relatively low chloride deposition rates, $35 \mathrm{mg} \mathrm{Cl} / \mathrm{m}^{2}$.day and $71 \% \mathrm{RH}$. This result may perhaps be related with the low rainfall recorded in these islands where the effect of removal of $\mathrm{NaCl}$ aerosol deposited in the rust layers by rain water is very little.

In Fig. 2 it can be seen how the corrosion rate greatly rises (trend curves shown in Fig. 2) when these critical thresholds for $\mathrm{RH}$ and atmospheric salinity are passed, clearly showing the extraordinary acceleration of the corrosion process due to the existence of akaganeite in the steel corrosion products. At high chloride deposition rates and $\mathrm{RH}$, and therefore high steel corrosion rates, all the studies considered in the elaboration of Fig. 2 indicate the formation of thick rust layers that are easily exfoliated and detached from the steel substrate.

\subsubsection{Morphological characterisation of akaganeite aggregates}

It is also of great interest to know the akaganeite morphology in the layer of corrosion products, where the confusion among researchers is well known.
The morphology of the different rust phases can be highly varied and depends on numerous factors such as the synthesis method used in the laboratory, formation conditions in the atmosphere, etc. The literature is lacking in rigorous studies on the morphology of the different rust phases found in rust layers formed on the surface of carbon steels as a consequence of exposure in different types of atmospheres. Mention may be made of the work of Raman et al. (Razvan and Raman, 1986; Raman et al., 1987), who used SEM to identify the rust phases formed on weathering steels on bridges in Lousiana, USA, in comparison with the morphology of rusts synthesised in the laboratory and identified by infrared spectroscopy. Many other researchers have published papers assigning SEM morphologies to the different phases, but their interpretations are often not backed up by an unequivocal analytical check.

In the case of akaganeite there is an even greater lack of references in the literature to rigorous studies on the morphologies of this phase formed in marine atmospheres. In the same way some researchers have assigned SEM morphologies to akaganeite without an unequivocal characterization of that oxyhydroxide (Sagoe-Crentsil and Glasser, 1993; Ma et al., 2009; Castaño et al., 2010; Morcillo et al., 2011).

Akaganeite is one of the polymorphs of ferric oxyhydroxides $(-\mathrm{FeOOH})$. Its formation requires halogen ions, $\mathrm{Cl}^{-}$or $\mathrm{F}^{-}$, to stabilise its crystalline structure (Mackay, 1960; Turgoose, 1982; Cornell 
and Schwertmann, 1996). Since it always contains chloride ions, the compound is not strictly speaking an oxyhydroxide. Ståhl et al. (2003) have determined its chemical formula as $\mathrm{FeO}_{0.833}(\mathrm{OH})_{1.167} \mathrm{Cl}_{0.167}$, designating it in general terms as $\mathrm{FeO}_{1-2 \mathrm{X}}(\mathrm{OH})_{1+\mathrm{X}} \mathrm{Cl}_{\mathrm{X}}$.

The akaganeite crystals are very small and the crystallographic structure is isostructural with hollandite $\left(\mathrm{BaMn}_{8} \mathrm{O}_{16}\right)$ (Mackay, 1960) characterised by the presence of tunnels parallel to the $\mathrm{C}$-axis of the lattice (Bystrom and Bystrom, 1950). Akaganeite displays two basic morphologies: somatoids (spindleshaped crystals) and rods (cigar-shaped crystals). In both the size distribution of the crystals is fairly narrow and their length is only exceptionally greater than $500 \mathrm{~nm}$ (Mackay, 1960).

With regard to the location of akaganeite in the corrosion product layer formed on steel in exposure to marine atmospheres, considerable controversy exists and this matter is still open to discussion, as noted by Rémazeilles and Refait (2007). According to many authors (Turgoose, 1982; Selwyn et al., 1999; Dillmann et al., 2004; Neff et al., 2005) akaganeite forms mainly in the inner part of the corrosion layer near the metal-oxide interface of corroded steel. But akaganeite has also been identified in the outer part of thick rust layers formed on carbon steels exposed to air in a coastal region (Asami and Kikuchi, 2003).

With regard to the suitability of the different analytical techniques for characterising akaganeite, XRD has been one of the most widely used and its diffractogram shows a characteristic high intensity peak at $56.36^{\circ}$, although Nishimura et al. (2000) use the diffraction peak at $11.84^{\circ}$. However, in our researches, when akaganeite is found in a low proportion in the corrosion product layer its presence can sometimes go unnoticed, requiring complex adjustments (Rietveld method) of the different rust phases probably present in order to detect its presence. At other times, such as in the case of thick rust layers and when akaganeite is found in innermore strata, its detection may at times go unnoticed when the XRD spectrum is obtained.

The morphology of very fine particles like akaganeite should in principle be observable by SEM, but rust particles always strongly agglomerate so it is difficult to observe the morphology of primary particles. In general, most of the SEM studies of rust formations in marine atmospheres have been carried out at relatively low magnifications (Ma et al., 2009; Castaño et al., 2010); so the existence of typical akaganeite crystals has not been seen since these are of a very small size, generally less than $100 \mathrm{~nm}$ in thickness and a length that rarely exceeds $500 \mathrm{~nm}$. SEM images prepared at higher magnifications in our study allowed the observation of the typical rod-shaped akaganeite crystals (Fig. 3) (Morcillo et al., 2015).

The singular morphology shown in Fig. 3a may be referred to as "sponge-type". The porous structure
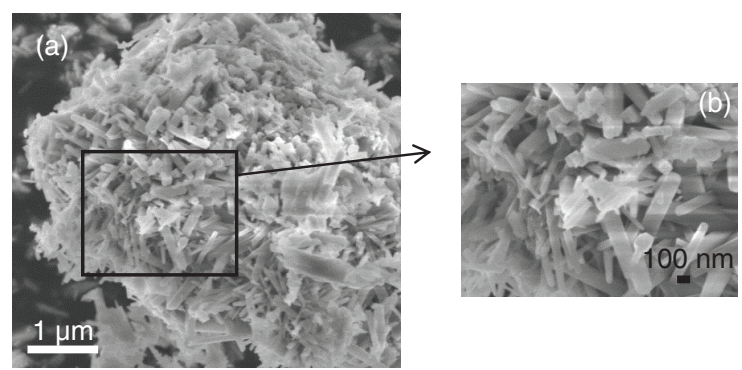

FIGURE 3. (a) SEM micrograph corresponding to aggregates of akaganeite particles; (b) Enlargement of the previous micrograph showing areas rich in elongated crystals.

of akaganeite agglomerates offers a very low protective capacity, leaving enormous gaps through which aggressive agents from the atmosphere can easily pass, thereby promoting the high corrosion rates of the underlying steel, characteristic of this type of atmospheres with high $\mathrm{Cl}^{-}$ion contents.

In order to precisely identify the presence of akaganeite in marine atmospheric corrosion products on mild steel, use has been made of transmission electron microscopy (TEM)/electron diffraction (ED) and $\mu$ Raman spectroscopy. TEM/ED analysis was performed on a rust sample of an orangey colour corresponding to the exfoliated steel/rust interface after one year of exposure of the steel to a highly chloride-rich atmosphere. $\mu$ Raman spectroscopy was carried out on a residual rusted steel surface following exfoliation of the thick rust layer formed, a phenomenon that will be discussed in detail below.

Figure 4a shows a TEM micrograph corresponding to an aggregate of crystals showing the same elongated morphology observed by SEM (Fig. 3b). Figure $4 \mathrm{~b}$ clearly shows the prismatic form of these akaganeite nanoparticles (cigar-shape crystal). The most characteristic SAED pattern observed in the crystals with this morphology is shown in Fig. 4c. This pattern can be indexed on the basis of a monoclinic cell of parameters 1.06, 0.303, $1.05 \mathrm{~nm}$ and $\beta=90.24^{\circ}$ along the $[-1-11]$ zone axis characteristic of the hollandite structural type corresponding to $\beta-\mathrm{FeOOH}$. The corresponding high resolution image (Fig. 4d) shows d-spacing of $0.74 \mathrm{~nm}\left(\mathrm{~d}_{101}\right)$ and $0.28 \mathrm{~nm}\left(\mathrm{~d}_{121}\right)$ corresponding to the akaganeite structure along [-1-11]. The Fourier transform and the calculated SAED pattern along this projection clearly demonstrate that these crystals show the structural features corresponding to akaganeite.

On the residual base steel from which the thick exfoliated rust layer was detached a study by SEM/ EDS and SEM/ $\mu$ Raman was carried out. In the SEM micrograph of Fig. 5a is possible to see the typical "doughnut" formation related with magnetite in the form of circular discs with bulging around their periphery (Raman et al., 1989). Around the magnetite discs the formation of a very porous 

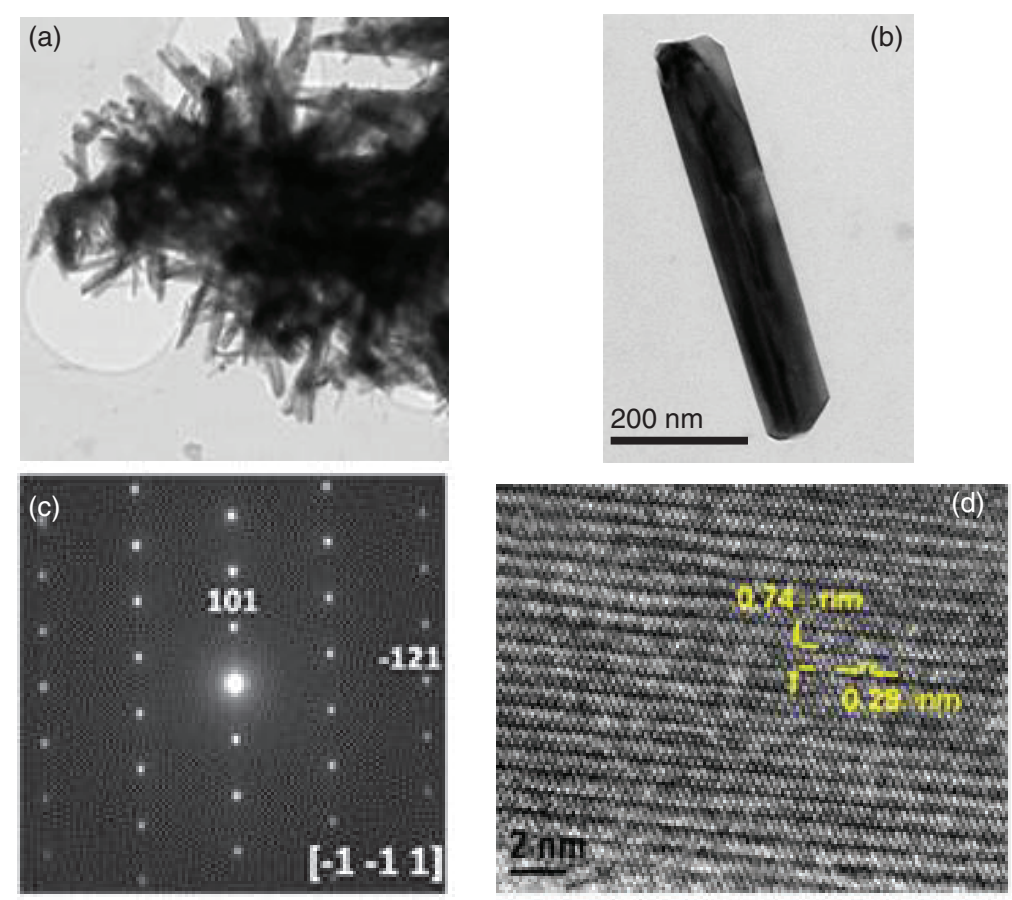

FIGURE 4. (a) TEM micrograph showing the aggregate of elongated crystals; (b) TEM micrograph of one of the nanoparticles constituting the aggregate shown in (a); (c) Indexed SAED pattern along the [-1-11] zone axis; (d) HREM image showing $\mathrm{d}$-spacing of $0.74 \mathrm{~nm}\left(\mathrm{~d}_{101}\right)$ and $0.28 \mathrm{~nm}\left(\mathrm{~d}_{-121}\right)$ corresponding to the akaganeite structure along [-1-11].

(a)

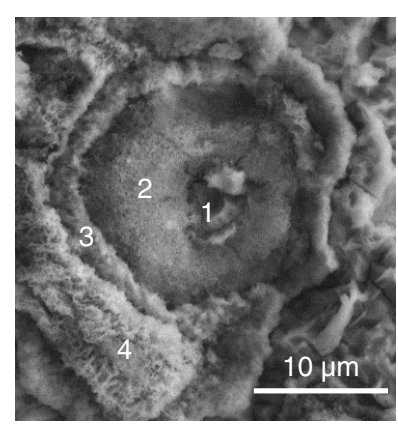

(b)

\begin{tabular}{lccc}
\hline \multirow{2}{*}{ Spectrum } & \multicolumn{3}{c}{ wt. \% } \\
\cline { 2 - 4 } & $\mathbf{O}$ & $\mathbf{C l}$ & Fe \\
\hline 1 & 31.4 & 0.5 & 68.1 \\
2 & 31.9 & 0.8 & 67.4 \\
3 & 24.9 & 4.3 & 70.9 \\
4 & 36.5 & 5.6 & 57.9 \\
\hline
\end{tabular}

(c)

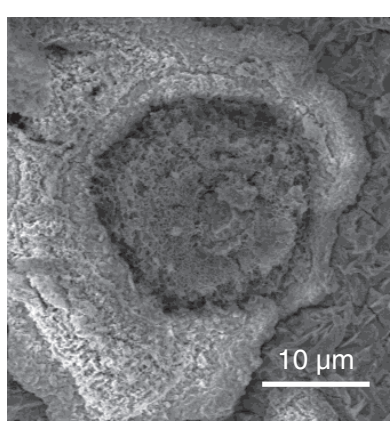

FIGURE 5. SEM views of a typical "doughnut" of magnetite formed on mild steel exposed to a very rich chloride atmosphere. The EDS analysis in different zones in (a) is shown (b).

and voluminous corrosion product take place, as clearly shown in secondary electron SEM image (Fig. 5c); the EDS elemental analysis present a very high chlorine signal, both at the crown around the doughnut and in a wider more outer area (Fig. 5b). The SEM micrograph in that outer area (Figs. 6a, b) 
(a)

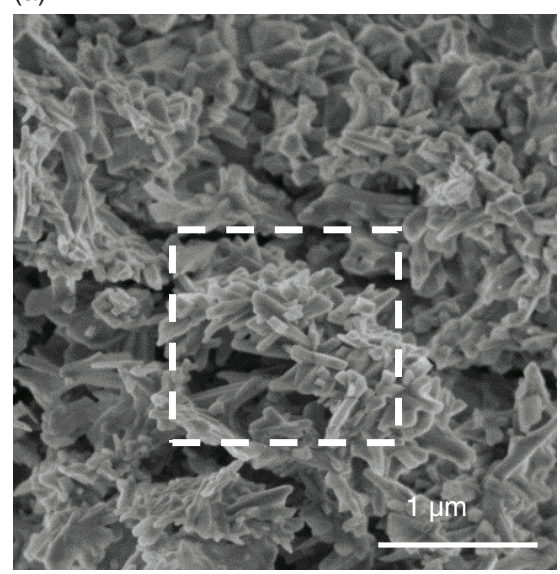

(b)

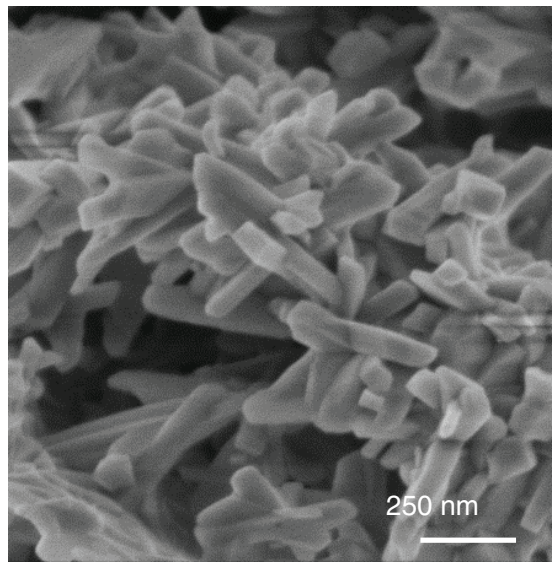

(c)

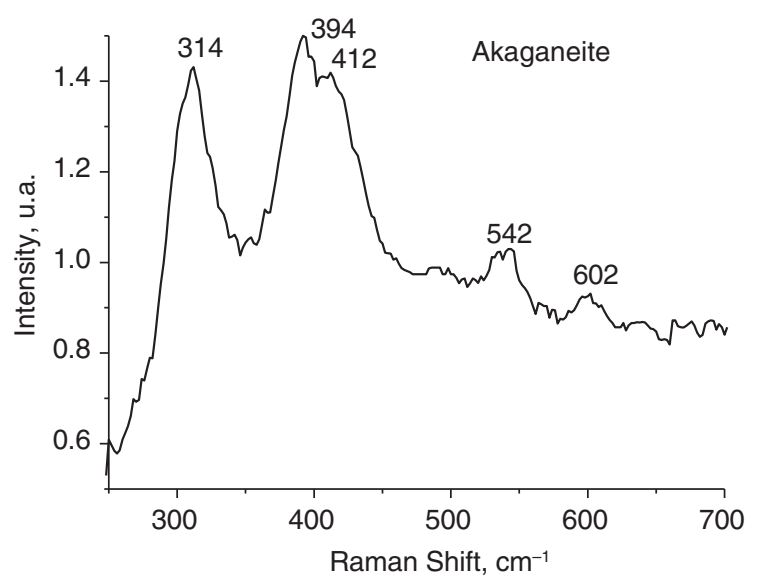

FIGURE 6. (a) SEM micrograph corresponding to aggregates of akaganeite nanocrystals; (b) Enlargement of the marked area of the previous micrograph. The Raman spectra (c) show the presence of akaganeite.

show a mesh of elongated cylinder or tube-type crystals that remind us the typical akaganeite nanocrystals shown in Figures 3 and 4. The Raman spectrum obtained in that zone (Fig. 6c) show the characteristic peaks of akaganeite.

\subsection{Corrosion mechanisms of carbon steel in chloride-rich atmospheres}

In view of the information obtained in the researches conducted in the pure marine atmospheres at Cabo Vilano wind farm, with different levels of chloride deposition, there seem to be two notably different situations with regard to the mild steel atmospheric corrosion mechanisms involved: (a) establishment of a consolidated, adherent and continuous rust layer (in lower salinity atmospheres), and (b) formation of an exfoliated rust layer that is easily detached from the base steel leaving large areas of this uncovered (in higher chloride deposition rate atmospheres).
In the first case, in which a "consolidated layer" of corrosion products remains on the steel surface, the conditions are right for a diffusion-controlled corrosion mechanism to act, in which the aggressive species from the atmosphere $\left(\mathrm{O}_{2}, \mathrm{H}_{2} \mathrm{O}, \mathrm{Cl}^{-}\right)$pass through the rust layer to interact with the underlying steel. The steel corrodes according to the anodic reaction of iron dissolution (Eq. 1), where the cathodic process consists of the reduction of oxygen dissolved in the moisture film (Eq. 2).

The $\mathrm{OH}^{-}$ions formed migrate towards the anodic zones forming $\mathrm{Fe}(\mathrm{OH})_{2}$ as the initial rust product:

$\mathrm{Fe}^{2+}+2 \mathrm{OH}^{-} \rightarrow \mathrm{Fe}(\mathrm{OH})_{2}$

The oxidation by oxygen from the air of $\mathrm{Fe}^{2+}$ ions produced as a consequence of the dissolution of $\mathrm{Fe}$ in the thin aqueous films formed in periods of wetting of the metallic surface, leads to the precipitation and crystallisation of lepidocrocite in the drying stage via the prior formation of $\mathrm{Fe}(\mathrm{OH})_{2}$. 
Strattmann et al. (1983), in an electrochemical study of phase transitions in already formed rust layers, proposed a three-stage rust formation mechanism (wetting, wet surface, and drying), demonstrating that the anodic reaction of iron dissolution in the first stage was not balanced by the cathodic reaction of reduction of the oxygen present in the moisture layer, but by the reduction of the pre-existing oxide, giving rise to a "reduced lepidocrocite" transition phase.

$\gamma$-FeOOH (lepidocrocite) $+\mathrm{H}^{+}+\mathrm{e}^{-} \rightarrow \gamma$-Fe.OH.OH (reduced lepidocrocite)

Once the reducible lepidocrocite is exhausted, importance is acquired by the cathodic reaction of reduction of the oxygen dissolved in the rust layer (Eq. 2), whose slow diffusion in the electrolyte-filled pores in the rust layer means that the metallic dissolution rate is highly limited. During drying, oxygen diffusion is extremely high due to the thinning of the electrolyte film, giving rise to high corrosion rates, where (Eq. 2) is the cathodic reaction, accompanied by the reoxidation of the previously formed reduced lepidocrocite to lepidocrocite.

\section{$2 \gamma-\mathrm{Fe} . \mathrm{OH} . \mathrm{OH}+1 / 2 \mathrm{O}_{2} \rightarrow 2 \gamma-\mathrm{FeOOH}+\mathrm{H}_{2} \mathrm{O}$}

According to Nishimura et al. (2000), in chloriderich atmospheres, more than the role played by lepidocrocite in the corrosion process of steel, as noted above for chloride-free atmospheres, the formation of akaganeite is the cause that extremely accelerates the atmospheric corrosion process. In a laboratory study these researchers saw that at low $\mathrm{Cl}^{-}$concentrations the oxyhydroxide that formed was lepidocrocite while high $\mathrm{Cl}^{-}$concentrations led to the formation of akaganeite via the formation of $\mathrm{Fe}(\mathrm{OH}, \mathrm{Cl})_{2.55}$, green rust (GR1). Thus they show that akaganeite can also be reduced electrochemically in the corrosion process, being consumed in the wetting period of the metallic surface. Subsequently, Lair et al. (2006) also experimentally saw that lepidocrocite was not the only species of the different phases comprising rust that was electrochemically reducible by $\mathrm{Fe}$ (galvanic couple), and that the order of reducing capacity was as follows: akaganeite $>$ lepidocrocite $>>$ goethite. The reduction of goethite by iron was not favoured, and if it occurred it would only be at an extremely low reaction rate.

In this mechanism, the steel corrosion rate will be influenced by the concentration of ionisable substances in the moisture film, as is the case of the chlorides present in marine atmospheres. In general there is a direct relationship between steel corrosion and the saline content of the atmosphere, as has been experimentally shown by numerous researchers (Alcántara et al., 2015).

However, the corrosion mechanisms that act on steel exposed to a very severe marine atmospheres (very high chloride deposition rates) can differ notably to that based on the existence of a "consolidated rust layer". In this new situation there is a notable acceleration of the corrosion process and the rust layers formed present heavy cracking and tend to exfoliate and become partly or completely detached from the base steel ("exfoliated rust layer"), which in turn presents heavy pitting with very deep pits. The high chloride concentration in the aqueous layer deposited on the metal and the high moisture retention in very deteriorated areas of the rust give rise to the formation of ferrous chloride, which hydrolyses the water:

$\mathrm{FeCl}_{2}+\mathrm{H}_{2} \mathrm{O} \rightarrow \mathrm{FeO}+2 \mathrm{HCl}$

notably raising the acidity of the electrolyte. In this situation the cathodic reaction the discharge of hydrogen ions (Eq. 3) becomes important, accelerating the corrosion process; the anolyte on the steel surface and in the pits that have formed becomes saturated (or close to saturation) with the highly acidic ferrous chloride solution. Both the metallic cations and the hydrogen ions require neutralisation, which occurs by the entry of chloride ions, but this leads to an increase in the chloride concentration which intensifies the metal dissolution, giving rise in turn to the entry of more chloride which further intensifies the corrosion process. This attack mechanism is fed by the corrosion products themselves (feedback mechanism) and is sometimes referred to as "autocatalytic" (Shreir et al., 1993).

On the rusted steel surface, which as a result of exfoliation had lost the rust layer formed, $\mathrm{pH}$ indicator strips (Merck MColorpHast ${ }^{\mathrm{TM}}$ ) were used to measure a $\mathrm{pH}$ of 5 , which dropped to 4 when the residual rust layer was removed by gentle brushing to expose the highly pitted surface of the base steel. This indicates the acidification of the steel/rust interface area on the specimens exposed to the very saline atmospheres.

According to Nomura et al. (1988) high concentrations of chloride and acidic conditions at the steel/rust interface lead to the formation of akaganeite and magnetite in the interior of the rust layer, close to the steel substrate where the access of oxygen from the air is more limited, by the transformation after a certain time of basic $\mathrm{Cl}^{-}$-containing iron complexes and slow oxidation of $\mathrm{Fe}$, respectively. In a recent paper, Shibata (2014) also noted that in an oxygen-depleted environment $\mathrm{H}_{2} \mathrm{O}$ works as an oxidising agent to oxidise $\mathrm{Fe}$ to produce $\mathrm{Fe}_{3} \mathrm{O}_{4}$ with the evolution of $\mathrm{H}_{2}$ gas:

$3 \mathrm{Fe}+4 \mathrm{H}_{2} \mathrm{O} \rightarrow \mathrm{Fe}_{3} \mathrm{O}_{4}+4 \mathrm{H}_{2}$

Therefore an oxygen deficit and the presence of high $\mathrm{Cl}^{-}$contents are fundamental factors for the 
formation of akaganeite and magnetite. Rémazeilles and Refait (2007), in an interesting laboratory study controlling the reaction of $\mathrm{Fe} \mathrm{Cl}_{2} \cdot 4 \mathrm{H}_{2} \mathrm{O}$ with $\mathrm{NaOH}$ by varying the $\mathrm{R}=\left[\mathrm{Cl}^{-}\right] /\left[\mathrm{OH}^{-}\right]$ratio, observed that for $\mathrm{R} \geq 8$, i.e. in conditions of a high excess of ferrous chloride, only akaganeite forms via the formation of intermediate GR 1 compounds, while with small excesses of $\mathrm{FeCl}_{2}$ only lepidocrocite forms. When $\mathrm{R} \leq 6$, goethite forms, and when $6.5 \leq \mathrm{R} \leq 8$, goethite and akaganeite form. The akaganeite formation mechanism implies the presence of high $\mathrm{Cl}^{-}$concentrations and acid conditions ( $\mathrm{pH}$ 4-6) due to the hydrolysis of ferrous chloride $\left(\mathrm{FeCl}_{2}\right)$, conditions that occur in confined spaces where $\mathrm{Cl}^{-}$ions accumulate, such as the metal/corrosion product interface, crevice zones, etc. This explains how the different situations that can be found at the steel/rust interface, depending on the $\mathrm{R}$ ratio value, can give rise to the formation of the three iron oxyhydroxides lepidocrocite, goethite and akaganeite, as has happened on the mild steel specimens exposed in high chloride deposition rate atmospheres (Alcántara et al., 2015).

\subsection{Rust exfoliation on carbon steel exposed to chloride-rich atmospheres}

The exposure of carbon steel in marine atmospheres can lead in certain circumstances to the formation of thick rust layers (containing a number of "compact laminas") that are easily detached (exfoliated) from the steel substrate, leaving it unprotected and considerably accelerating the corrosion process. This deterioration phenomenon is of particular concern in steel infrastructures located close to the sea (civil constructions, bridges, etc.), whose service lifetime can be extraordinarily limited. High times of wetness of the metallic surface and high chloride ion deposition rates play a decisive role in the formation of this type of rust. This particular kind of damage is not only limited to marine atmospheres with high chloride ion deposition rates. Although typically associated with marine environments, chlorides are actually also prevalent in the environment from the use of road de-icing salts.

Few scientific studies have specifically addressed this singular type of rust, which is referred to in the literature under different names: sheet-type rust (Raman, 1988), stratified rust (Raman, 1988), exfoliated rust (Cook, 2005), multilayered rust (Hara, 2008), etc. Figure 7 presents cross-section optical micrograph obtained on the exfoliated layer produced on a mild steel specimen exposed for one year at the highest chloride deposition rate atmosphere of Cabo Vilano. Laminas of different thicknesses can be seen in the exfoliated layer and also the presence loose rust strata between the laminas (interlaminar rust).

With the assistance of a very thin sharp blade, a compact lamina was carefully separated from the exfoliated rust layer formed on the mild steel

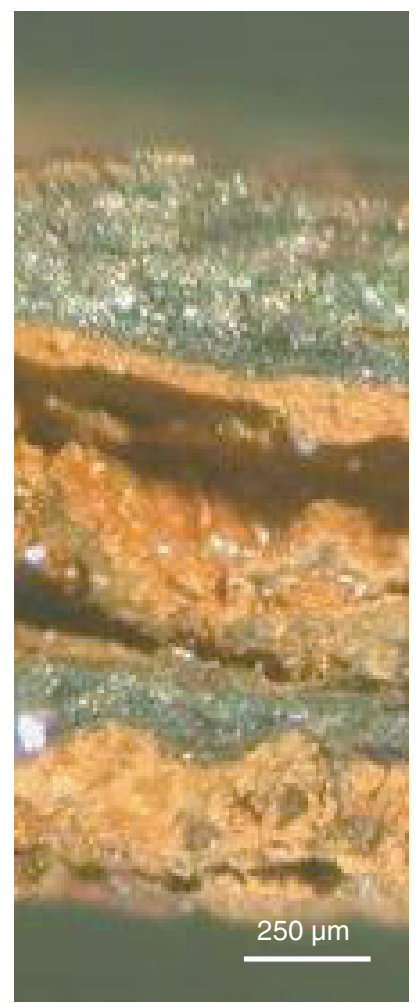

FIGURE 7. Cross-section of exfoliated rust layers composed by different rust strata: optical micrograph showing two compact laminas and interlaminar rust layer between them.

specimen (skyward side) exposed for 6 months at that atmosphere. X-ray diffractograms were obtained from the outer and inner surfaces of the lamina. The lamina was then ground to obtain fine powder for quantitative analysis of the different rust phases present (Table 4). When analysing the XRD results obtained applying the Rietveld method it is seen how the spinel content in the bulk lamina (powdered) increases, while at the same time the lepidocrocite and akaganeite contents decrease.

It is important to discern the composition of the interior of the lamina and to know whether it is comprised by magnetite, maghemite or both. For this purpose, the lamina used in the previous XRD study, but powered, was also studied by Mössbauer spectroscopy, a technique that allows the differentiation of these two phases. The room temperature spectra recorded (Fig. 8) was fitted using three sextets and a paramagnetic doublet. The Mössbauer parameters obtained from the fit and the corresponding spectral areas are presented in Table 5. Sextet M1 has parameters characteristic of maghemite (Murad and Johnston, 1987). Sextet M2 has an isomer shift, $\delta$, which is typical of $\mathrm{Fe}^{3+}$, a low quadrupole shift, $2 \varepsilon$, which is not too different from that of sextet M1, and a hyperfine magnetic field, $\mathrm{H}$, lower than that shown by sextet M1. Sextet M2 is associated with a maghemite fraction of a smaller 
TABLE 4. Composition (wt. \%) of the different rust phases in different zones of the compact lamina in an exfoliated rust layer. Information obtained by XRD using the Rietveld fitting method

\begin{tabular}{lcccc}
\hline Zone in compact lamina & Lepidocrocite & Goethite & Akaganeite & Spinel \\
\hline Outer surface & 39 & 52 & $<1$ & 8 \\
Powdered lamina & 10 & 48 & $<1$ & 41 \\
Inner surface & 30 & 38 & 30 & 2 \\
\hline
\end{tabular}

particle size than that which gives rise to sextet M1 whose Mössbauer parameters are similar to those shown by bulk maghemite. In fact, the fit to two sextets is a simplification of the evident magnetic field distribution originated by the presence of a maghemite particle size distribution. The presence of magnetite can be ruled out since the sextet corresponding to the $\mathrm{Fe}^{2.5+}$ octahedral component of this oxide, which is characterised by a large isomer shift $\delta=0.6-0.7 \mathrm{mms}^{-1}$, is absent. The broad magnetic component M3 has Mössbauer parameters that can be associated in full certainty with the presence of goethite (Murad and Johnston, 1987). Finally, the Mössbauer parameters of the paramagnetic doublet do not allow unambiguous assignment since it may be due to either superparamagnetic goethite, lepidocrocite, or both. In order to ascertain the nature of this doublet, a spectrum was recorded at $16 \mathrm{~K}$. The $16 \mathrm{~K}$ spectrum recorded was fitted to three different magnetic components whose Mössbauer parameters are characteristic of maghemite, goethite and lepidocrocite (Murad and Johnston, 1987). Goethite is the most intense component in all cases as was also shown by the XRD results.

What is the formation of maghemite due to? Going back to Table 4 again, the increased presence of spinel (maghemite) when considering the interior of the lamina is directly linked to the reduction in the lepidocrocite and akaganeite contents. The following mechanism of transformation of both oxyhydroxides in maghemite is proposed. Firstable occurs the formation of magnetite at expense of the electrochemical reduction of akaganeite and lepidocrocite, as proposed by Tanaka et al. (2014).
$\mathrm{Fe}^{2+}+8 \mathrm{FeOOH}+2 \mathrm{e}^{-} \rightarrow 3 \mathrm{Fe}_{3} \mathrm{O}_{4}+4 \mathrm{H}_{2} \mathrm{O}$

Then, in the dry state magnetite is readily oxidised to maghemite by air (Cornell and Schwertmann, 1996).

$4 \mathrm{Fe}_{3} \mathrm{O}_{4}+\mathrm{O}_{2} \rightarrow 6 \mathrm{Fe}_{2} \mathrm{O}_{3}$

In any case, it would be necessary to carry out specific research addressing this point in order to exactly clarify the responsible mechanisms involved in the formation of maghemite. The authors of this work are currently engaged in research in this respect.

A possible mechanism of rust exfoliation is proposed below:

The corrosion product layer initially formed would be composed of the different oxyhydroxides (lepidocrocite, goethite and akaganeite) and iron oxide (magnetite), common in the atmospheric corrosion of steel in marine atmospheres. The high times of wetness and abundant formation of akaganeite in these severe marine atmospheres (Morcillo et al., 2015) would boost the atmospheric corrosion process during the wet/dry cycles, giving rise to thick rust layers. Simultaneously the electrochemical reduction of akaganeite and lepidocrocite would give rise to the formation of magnetite, then transformed to maghemite as noted above.

The growth of the corrosion product layer may stop due to excessive drying by seasonal effects. During episodes of extreme drying, the large temperature fluctuations may induce also stresses in the rust layers which promote debondment of the rust that has been formed from the underlying steel. Subsequently, once the dry period has come to an

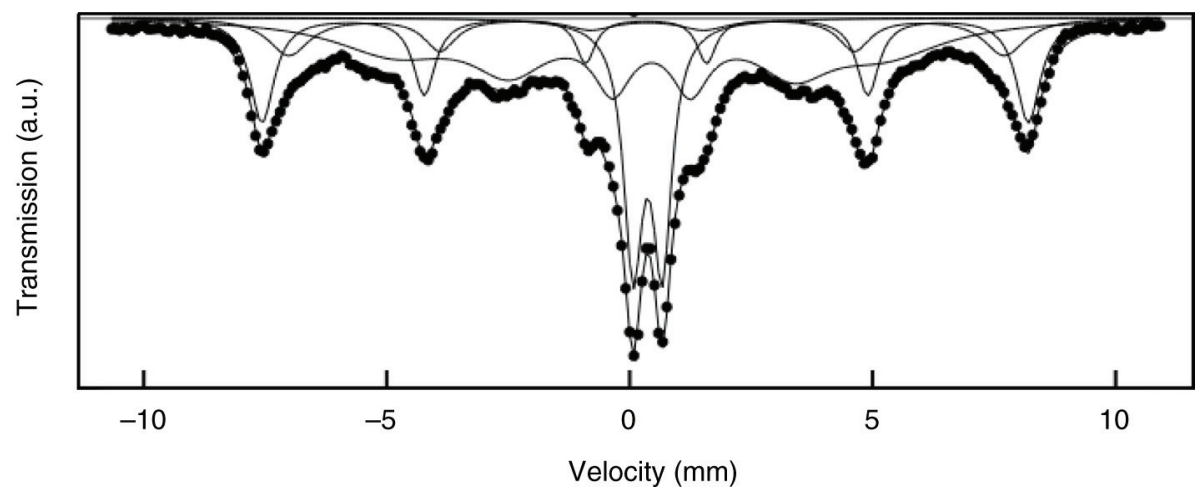

FIGURE 8. Mössbauer spectra recorded from the powdered lamina at room temperature. 
TABLE 5. Mössbauer parameters and relative spectral areas obtained from the fit of the room temperature spectra

\begin{tabular}{lcccc}
\hline & Sextet M1 & Sextet M2 & Sextet M3 & Doublet \\
\hline$\delta, \mathrm{mm}_{\mathrm{s}} \mathrm{s}^{-1}$ & 0.35 & 0.36 & 0.35 & 0.36 \\
$2 \varepsilon, \Delta^{\mathrm{a}}, \mathrm{mm} \cdot \mathrm{s}^{-1}$ & -0.01 & -0.03 & -0.23 & 0.60 \\
$\mathrm{H}(\mathrm{T})$ & 48.9 & 45.8 & 30.9 & - \\
Outer lamina & 22 & 14 & 44 & 20 \\
Inner lamina & 24 & 14 & 48 & 15 \\
Assignment & Maghemite & Maghemite & Goethite & Lepidocrocite/Spmgoethite \\
\hline
\end{tabular}

$\delta=$ isomer shift; $2 \varepsilon=$ quadrupole shift; stands for sextets; $\Delta^{\mathrm{a}}=$ quadrupole splitting, stands for doublets; $\mathrm{H}=$ hyperfine magnetic field

end, the formation of a second lamina would begin, and so on. Figure 9 shows a feasible scheme of the different stages in the formation of rust layers in the rust exfoliation process. However, all of this is merely a conjecture that must be clarified by specific research focused on this issue, as has been noted above.

\subsection{Long-term prediction of atmospheric corrosion of mild steel in marine atmospheres}

For long-term atmospheric corrosion the power function
$\mathrm{C}=\mathrm{At} \mathrm{t}^{\mathrm{n}}$

where, $\mathrm{C}$ is the corrosion after time $\mathrm{t}$, and $\mathrm{A}$ and $\mathrm{n}$ are constants, has been widely used.

According to Benarie and Lipfert (1986), Eq. (11) is a mass-balance equation showing that the diffusion process is rate-determining, and this rate depends on the diffusive properties of the layer separating the reactants. The exponential law, Eq. (11), with $n$ close to 0.5 , can result from an ideal diffusion-controlled mechanism when all the corrosion products remain on the metal surface. This situation seems to occur

Initiation of the second lamina formation

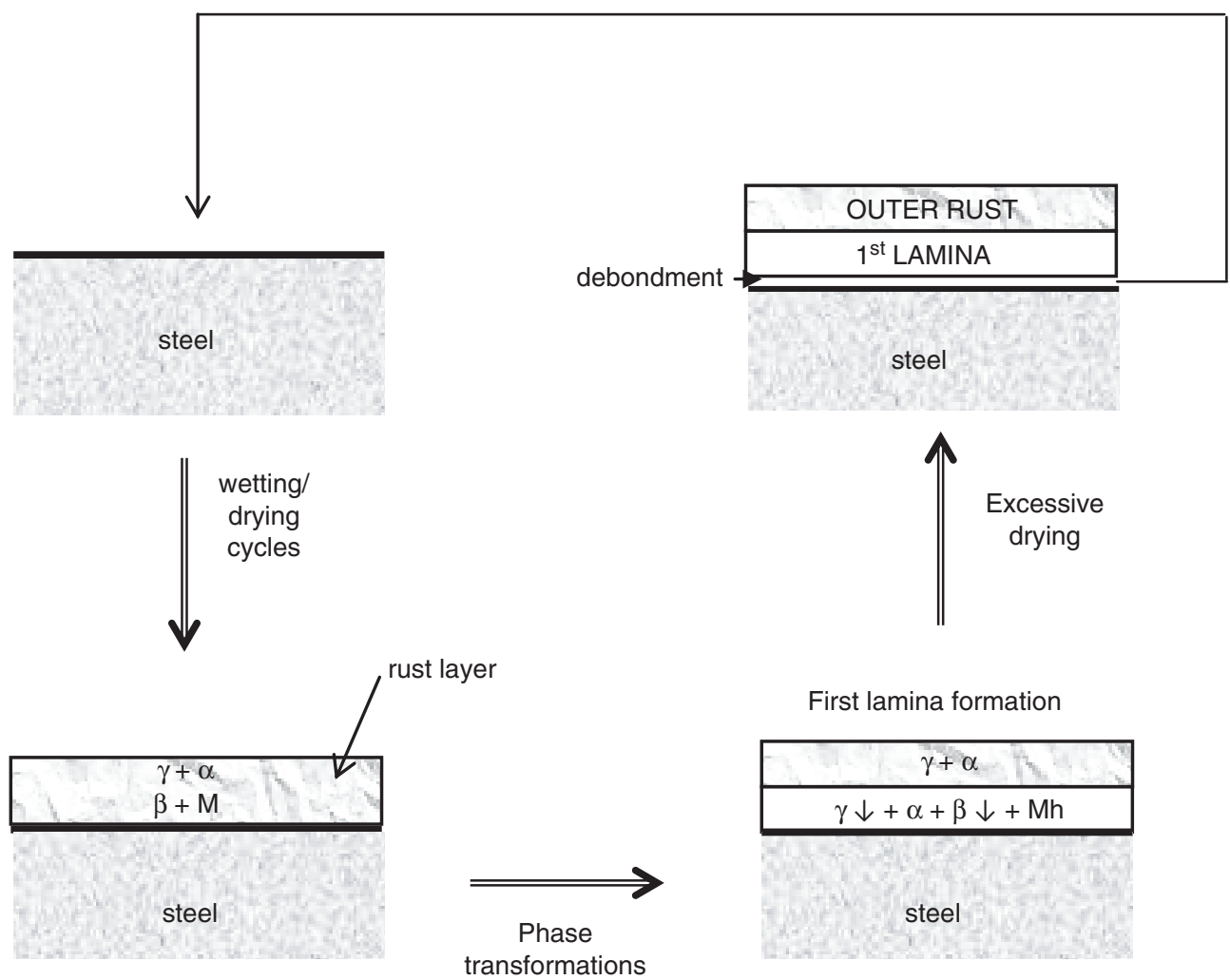

FIGURE 9. Scheme of the feasible exfoliation mechanism of carbon steel exposed to severe marine atmospheres. Lepidocrocite $(\gamma)$, goethite $(\alpha)$, akaganeite $(\beta)$, magnetite $(M)$ and maghemite $(\mathrm{Mh})$. 
in slightly polluted inland atmospheres. On the other hand, $n$ values of more than 0.5 arise due to acceleration of the diffusion process. This situation is typical of marine atmospheres, even those with low chloride contents. Conversely, $n$ values of less than 0.5 result from a decrease in the diffusion coefficient with time through recrystallization, agglomeration, compaction, etc. of the rust layer (Morcillo et al., 1993).

According to Benarie and Lipfert (1986), as a rule $\mathrm{n}<1$ and there is no physical sense for $\mathrm{n}>1$, as $\mathrm{n}=1$ is the limit for unimpeded diffusion (high permeable corrosion products or no layer at all). Thus, values of $n>1$ have been dismissed in many atmospheric corrosion studies as being due to outliers in mass loss determinations. However, as noted in section 3.2, the corrosion mechanism that acts on steel exposed to very severe marine atmospheres can differ notably from that based on the existence of a consolidated layer of corrosion products through which diffusion processes involving aggressive species from the environment take place. In very severe marine atmospheres, rust layers present heavy cracking and tend to exfoliate and become partly or completely detached from the base steel. For this reason, in highly severe marine atmospheres, Eq. (4) -based on diffusion mechanisms- cannot sometimes be applicable. When applied, it is very common to find exponent $n$ values of close to 1 or even values of $n>1$ due to acceleration of the corrosive attack as a result of the aforementioned mechanisms (see Section 3.2). Figure 10 shows the evolution of steel corrosion with exposure time in marine atmospheres with high deposited chloride ion contents. The acceleration of the attack as exposure time advances is evident (Morcillo et al., 1998; Hou and Liang, 1999).

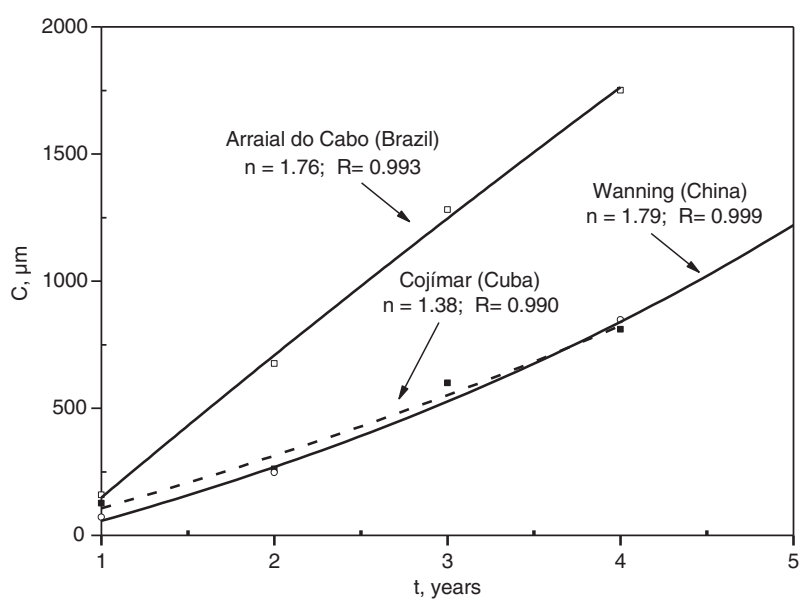

FIgURE 10. Evolution of mild steel corrosion with exposure time in severe marine atmospheres: Wanning, China (Hou and Liang, 1999), Arraial do Cabo, Brazil (Morcillo et al., 1998), and Cojímar, Cuba (Morcillo et al., 1998). Values of exponent $n$ and correlation coefficient $(R)$ have been obtained from $\log C$ - $\log t$ plots for each sie.
There is unfortunately a shortage of data in the literature on steel atmospheric corrosion for long exposure times in varied marine atmosphere exposure conditions; the shortage is even more noticeable for severe marine atmospheres. Only by the analysis of such data will it be possible to establish what mathematical relationships would be most consistent to define the kinetics of the atmospheric corrosion process and be able to predict the long-term behaviour of steel in severe marine atmospheres.

\subsection{Behaviour of weathering steels in marine atmospheres}

Weathering steels (WS), also known as low-alloy steels, are steels with a carbon content of less than 0.2 wt. \% to which mainly $\mathrm{Cu}, \mathrm{Cr}, \mathrm{Ni}, \mathrm{P}, \mathrm{Si}$ and $\mathrm{Mn}$ are added as alloying elements to a total of no more than 3-5 wt. \% (Murata, 2000). The enhanced corrosion resistance of WS in relation to mild steel or plain carbon steel (CS) is due to the formation in low aggressive atmospheres of a compact and welladhering corrosion product layer known as patina.

A matter of the greatest practical relevance is to know when an unpainted WS can be used. The problem is how to define the environmental conditions of an atmosphere of moderate aggressivity, which is ultimately what determines the applicability of an unpainted WS. From a practical point of view, the criterion followed has been to limit the steady-state corrosion rate of WS in the atmosphere to an acceptable value for material safety, where maintenance operations are not required (Kihira and Kimura, 2011).The fairly widespread criterion of $\leq 5-6 \mu \mathrm{m} /$ year for long-term atmospheric corrosion suggests only a marginal benefit of using conventional WS in preference to CS in aggressive atmospheres, especially in marine atmospheres (Cook, 2005). Thus, Morcillo et al. (2013) suggest that unpainted conventional WS should not be used in atmospheres of ISO corrosivity category $\geq$ C3 (EN ISO 9223, 2012) marine or otherwise.

As was commented in Experimental in our research two types of WS have been considered: one conventional WS (Cor-Ten A, ASTM A-242 (2007)) and one advanced WS, that Nippon Steel has designed specifically for coastal atmospheres (Nippon Steel Corporation, 2006). One mild steel was also used for comparative purposes. The compositions of steels were given in Table 3. Except where the atmospheric salinity is the lowest and three steels show similar corrosion rates after one year of exposure (Fig. 11), at all the remaining testing stations the weathering steels present better behaviour than the mild steel, in the order: AWS $>$ CWS $>$ MS.

The higher the atmospheric salinity of the exposure site, the more the differences in behaviour are accentuated. Although one year of atmospheric exposure is not long enough to reach the steady state, 


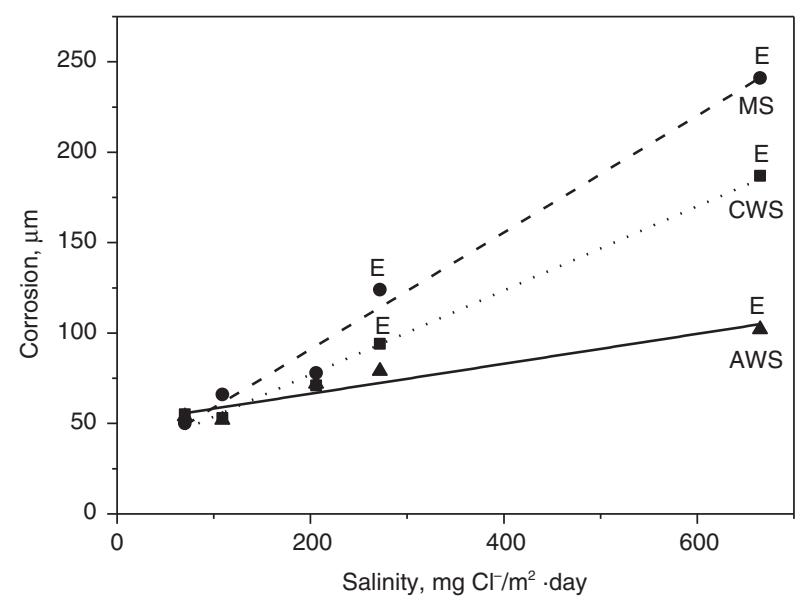

FIGURE 11. Corrosion of steels versus salinity of the atmosphere. Data corresponding to 12 months of exposure. The letter $E$ indicates the situations where exfoliation of the rust layers was observed.

the AWS corrosion rates found in the considered marine atmospheres seem to be much higher than the established criterion of 5-6 $\mu \mathrm{m} /$ year which allows their use without paint. Even so, the presence of Ni in the WS composition is seen to promote greater corrosion resistance in marine atmospheres after only one year of exposure. (Díaz et al., 2013). The presence of $\mathrm{Ni}$ in the steel raises the proportion of nanophasic or supermagnetic goethite (particle size smaller than $15 \mathrm{~nm}$ ) which increases its compactness and its resistance to atmospheric corrosion, as we found in our studies (Cano, 2013; Díaz, 2012; Díaz et al., 2013).

The formation of anomalous thick rust layers accompanies the exfoliation phenomenon as has been considered in Section 3.3. In the graphs in Fig. 11 the letter $\mathrm{E}$ indicates the cases in which exfoliation of the rust layers has been observed. It would seem that the annual steel corrosion needs to exceed a threshold of around $100 \mu \mathrm{m}$ in order for exfoliation to take place. After 12 months of exposure rust exfoliation is not observed on the AWS specimens at any of the testing stations, even those where the salinity is highest. For this same exposure time MS and CWS both present similar behaviour in relation with the appearance of exfoliation, which takes place when the chloride deposition rate exceeds a critical threshold of close to $300 \mathrm{mg} \mathrm{Cl}^{-} / \mathrm{m}^{2}$.day, obviously together with very high times of wetness of the metallic surface.

According to Ishikawa et al. the specific surface area (SA) of the rust decreases as the $\mathrm{NaCl}$ content in the atmosphere increases. Therefore, rust from coastal sites is composed of larger particles than at other sites. This finding suggests that $\mathrm{NaCl}$ promotes rust particle growth, resulting in the formation of larger pores as voids between larger particles in the rust layer and facilitating further corrosion (Ishikawa et al., 2001; Ishikawa et al., 2007). With regard to the granulometry of the outermost rust layer formed on the steel surface, the rust formed at corrosion stations with the lowest chloride deposition rates (Table 2), where exfoliation was not observed on any of the tested steels, showed a finer rust granulometry on the WS than on the MS, in the order: AWS < CWS < MS.

Ishikawa et al. (2006) found that alloying with $\mathrm{Ni}$ reduced the particle size of the rusts formed in $\mathrm{Cl}^{-}$environments and thought that the high corrosion resistance of $\mathrm{Ni}$-alloying steel is ascribed to the formation of dense rust layers composed of fine particles. On other side, these researchers found that the anticorrosive character of $\mathrm{Ti}$ in $\mathrm{Cl}^{-}$containing environment can be attributed to the specific inhibitory effect of Ti(IV) on the formation of akaganeite; metal ions of Ti(IV) drastically influences the crystallization and particle growth of akaganeite (Ishikawa et al., 2004). Thus, a very important scientific field, for the development of new coastal WS, is opened.

\section{CONCLUSIONS}

The following general conclusions may be drawn from this work:

- The chloride deposition rate at the exposure site (atmospheric salinity) plays a decisive influence on the marine atmospheric corrosion of carbon steel. Depending on the atmospheric salinity level, the structure of the corrosion product layers formed on the steel surface presents two extreme situations, which go from the formation of a "consolidated rust layer" (at relatively low salinities) to the formation of highly imperfect and cracked thick exfoliated rust layer (at very high salinities) which is easily detached from the residual base steel.

- The atmospheric corrosion mechanisms in these two situations are completely different. In the case of a "consolidated rust layer", a diffusioncontrolled corrosion mechanism takes place, in which the aggressive species from the atmosphere $\left(\mathrm{O}_{2}, \mathrm{H}_{2} \mathrm{O}, \mathrm{Cl}^{-}\right)$pass through the rust layer to interact with the underlying steel. The predominant cathodic reaction is the reduction of oxygen dissolved in the aqueous film. The corrosion rate is dependent on the chloride ion concentration in the atmosphere. These ions become incorporated in the condensed moisture films or aqueous films deposited on the steel surface and accelerate the atmospheric corrosion process. The corrosion products formed are composed mainly of lepidocrocite and goethite, and to a lesser extent magnetite and akaganeite.

- In the case of an "exfoliated rust layer", the high chloride concentration in the aqueous layer 
deposited on the steel surface gives rise to the formation of ferrous chloride, which hydrolyses the water, notably raising the acidity of the electrolyte. In this situation the cathodic reaction of hydrogen evolution becomes important, accelerating the corrosion process (autocatalytic mechanism). The high chloride concentration, acidic conditions, and oxygen depletion at the steel/rust interface lead to the formation of high akaganeite and magnetite contents in the rust layer.

- The exfoliated rust layer is composed of different strata, alternating between highly consistent and compact rust layers (laminas) and very porous and of low consistency rust layers (interlaminar rust). The interior of the laminas is highly maghemite rich, while the interlaminar rust presents major goethite and akaganeite contents.

- Detachment of the thick rust layer from the steel substrate takes place when there is a considerable thickness of corrosion products and the debondment stresses originated between the corrosion product layer and the substrate due to temperature fluctuations exceed the adhesion forces between both.

- $\quad$ The advanced WS (2.83 wt. $\%$ Ni, 0.28 wt. $\% \mathrm{Cu})$ shows greater resistance to rust exfoliation than the mild steel or the conventional weathering steel (ASTM A-242) of lower marine atmospheric corrosion resistance.

- In general, the atmospheric environmental conditions necessary for the formation of akaganeite are: an annual average relative humidity of around $80 \%$ or higher, and simultaneously an average annual chloride ion deposition rate of around $60 \mathrm{mg} / \mathrm{m}^{2}$.day or higher. A high chloride deposition rate in the atmosphere is not the only condition for the formation of akaganeite; the atmosphere must be characterised by high annual average RH and TOW as well.

- $\quad$ SEM/EDS observation at high magnifications $(>30,000)$ has revealed porous and voluminous akaganeite formations in rust areas with a "sponge type" morphology constituted by aggregates of elongated cylinder- or tube-type nanocrystals. TEM/SAED precisely identify the nature and structure of the cigar-shape crystals of akaganeite forming these aggregates.

- Dark discs (doughnut-like) are the typical SEM morphologies found for magnetite.

- For XRD quantification of rust phases in the corrosion products formed on mild steel exposed in marine atmospheres it is necessary to carry out fitting of the diffraction pattern using the Rietveld method. The semi-quantitative analysis performed by the Reference Intensity Ratio (RIR) method is subject to high inaccuracy due to systematic peak overlaps of the different rust phases.
- However, XRD cannot discriminate between cubic iron oxides, magnetite and maghemite. Both oxides crystallise in a spinel crystal structure and their lattice parameters are very similar, hence their diffractograms are practically identical. In the research use was made of Mössbauer Spectrosocpy, a technique that alloys the differentiation of these two phases.

- SEM/EDS, $\mu$ XRD and SEM/ $\mu$ Raman have been in this work also very useful experimental techniques to characterise the corrosion products and layers formed on mild steel exposed to chloride-rich atmospheres.

\section{ACKNOWLEDGEMENTS}

The authors gratefully acknowledge the financial support for this study from the Ministry of Science and Innovation of Spain (CICYT-MAT 2008-06649). The authors would like to express their gratitude to the companies ENEL and GAS NATURAL for the facilities provided and for allowing the location of the corrosion stations at Cabo Vilano wind farm (Camariñas, Spain). They would also like to thank the Spanish Meteorology Agency (AEMET) for the data provided on meteorological parameters in the study area. A special acknowledgement must be done to the research teams of the following researchers: Prof. P. Adeva (SEM/EDS), Prof. J.M ${ }^{\mathrm{a}}$ González-Calbet (TEM/ED), J.A. Jiménez (XRD), and J.F. Marco (Mössbauer Spectroscopy), as well as Hybriscan Technologies (Arnhem, The Netherlands) for SEM/MicroRaman measurements. I. Díaz also acknowledges the $\mathrm{PhD}$ scholarship financed by CSIC JAE Programme.

\section{REFERENCIAS}

EN ISO 9223 (2012). Corrosion of metals and alloys Corrosivity of atmospheres - Classification, determination and estimation, European Committee for Standardization, Brussels.

EN ISO 9225 (2012). Corrosion of metals and alloys - Corrosivity of atmospheres - Measurement of environmental parameters affecting corrosivity of atmospheres, European Committee for Standardization, Brussels

ISO 8407 (1991). Corrosion of metals and alloys - Removal of corrosion products from corrosion test specimens, International Organization for Standardization, Genève.

ASTM A-242/A-242M-04 (2007). Standard specification for high-strength low-alloy structural steel, American Society for Testing and Materials, Philadelphia.

Alcántara, J., Chico, B., Díaz, I., de la Fuente, D., Morcillo, M. (2015). Airborne chloride deposit and its effect on marine atmospheric corrosion of mild steel. Corros. Sci. (in press). http://dx.doi.org/10.1016/j.corsci.2015.04.015.

Antunes, R.A., Costa, I., de Faria, D.L.A. (2003). Characterization of corrosion products formed on steels in the first months of atmospheric exposure. Mater. Res. 6(3),403-408. http://dx.doi.org/10.1590/S1516-14392003000300015.

Asami, K., Kikuchi, M. (2003). In-depth distribution of rusts on a plain carbon steel and weathering steels exposed to coastal-industrial atmosphere for 17 years. Corros. Sci. 45 (11), 2671-2688. http://dx.doi.org/10.1016/S0010-938X (03)00070-2. 
Barton, K. (1973). Protection Against Atmospheric Corrosion. John Wiley and Sons, New York.

Benarie, M., Lipfert, F.L. (1986). A general corrosion function in terms of atmospheric pollutant concentrations and rain pH. Atmosph. Environ. 20 (10), 1947-1958. http://dx.doi. org/10.1016/0004-6981(86)90336-7.

Bystrom, A., Bystrom, A.M. (1950). The crystal structure of hollandite, the related manganese oxide minerals, and $\alpha-\mathrm{MnO}_{2}$. Acta Cryst. 3, 146-154. http://dx.doi.org/10.1107/ S0365110X5000032X.

Cano, H. (2013). Aceros patinables $(\mathrm{Cu}, \mathrm{Cr}, \mathrm{Ni})$ : Resistencia a la corrosión atmosférica y soldabilidad, Ph. Thesis, Complutense University, Madrid.

Castaño, J.G., Botero, C.A., Restrepo, A.H., Agudelo, E.A., Correa, E., Echeverría, F. (2010). Atmospheric corrosion of carbon steel in Colombia. Corros. Sci. 52 (1), 216-223. http://dx.doi.org/10.1016/j.corsci.2009.09.006.

Cook, D.C. (2005). Spectroscopic identification of protective and non-protective corrosion coatings on steel structures in marine environments. Corros. Sci. 47 (10), 2550-2570. http://dx.doi.org/10.1016/j.corsci.2004.10.018.

Cornell, R.M., Schwertmann, U. (1996). The Iron Oxides, Structure, Properties, Occurrence and Uses. VCH, Weinheim.

Díaz, I. (2012). Corrosión atmosférica de aceros patinables de nueva generación, Ph. Thesis, Complutense University, Madrid.

Díaz, I., Cano, H., de la Fuente, D., Chico, B., Vega, J.M., Morcillo, M. (2013). Atmospheric corrosion of Ni-advanced weathering steels in marine atmospheres of moderate salinity. Corros. Sci. 76, 348-360. http://dx.doi.org/10.1016/j.corsci. 2013.06.053.

Dillmann, P., Mazaudier, F., Hoerlé, S. (2004). Advances in understanding atmospheric corrosion of iron. I. Rust characterization of ancient ferrous artefacts exposed to indoor atmospheric corrosion. Corros. Sci. 46 (6), 1401-1429. http://dx.doi.org/10.1016/j.corsci.2003.09.027.

Hara, S. (2008). A X-Ray diffraction analysis on constituent distribution of heavy rust layer formed on weathering steel using synchrotron radiation. Corrosion Engineering 57 (2), 70-75. http://dx.doi.org/10.3323/jcorr.57.70.

Hara, S., Kamimura, T., Miyuki, H., Yamashita, M. (2007). Taxonomy for protective ability of rust layer using its composition formed on weathering steel bridge. Corros. Sci. 49 (3), 1131-1142. http://dx.doi.org/10.1016/j.corsci.2006.06.016.

Hiller, J.E. (1966). Phasenumwandlungen im Rost. Werkst. Korros.- Materials and Corrosion 17 (11), 943-951. http:// dx.doi.org/10.1002/maco.19660171104

Hou, W., Liang, C. (1999). Eight-year atmospheric corrosion exposure of steels in China. Corrosion 55 (1), 65-73. http:// dx.doi.org/10.5006/1.3283967.

Ishikawa, T., Isa, R., Kandori, K., Nakayama, T., Tsubota, T. (2004). Influences of metal chlorides and sulfates on the formation of $\mathrm{B}-\mathrm{FeOOH}$ particles by aerial oxidation of $\mathrm{FeCl}_{2}$ Solutions. J. Electrochem. Soc. 151, B586-B594. http://dx.doi.org/10.1149/1.1803837.

Ishikawa, T., Kumagai, M., Yasukawa, A., Kandori, K. (2001). Characterization of rust on weathering steel by gas adsoption. Corrosion 57 (4), 346-352. http://dx.doi.org/10.5006/ 1.3290358.

Ishikawa, T., Maeda, A., Kandori, K., Tahara, A. (2006). Characterization of Rust on Fe-Cr, Fe-Ni, and Fe-Cu Binary Alloys by Fourier Transform Infrared and N2 Adsorption. Corrosion 62 (7), 559-567. http://dx.doi.org/ $10.5006 / 1.3280669$

Ishikawa, T., Yoshida, T., Kandori, K., Nakayama, T., Hara, S. (2007). Assessment of protective function of steel rust layers by N2 adsorption. Corros. Sci. 49 (3), 1468-1477. http://dx.doi.org/10.1016/j.corsci.2006.08.020.

Kihira, H., Kimura, M. (2011). Advancements of weathering steel technologies in Japan. Corrosion 67 (9), 1-13. http:// dx.doi.org/10.5006/1.3628684.

Lair, V., Antony, H., Legrand, L., Chaussé, A. (2006). Electrochemical reduction of ferric corrosion products and evaluation of galvanic coupling with iron. Corros. Sci. 48 (8), 2050-2063. http://dx.doi.org/10.1016/j.corsci.2005. 06.013.
Ma, Y., Li, Y., Wang, F. (2009). Corrosion of low carbon steel in atmospheric environments of different chloride content. Corros. Sci. 51 (5), 997-1006. http://dx.doi.org/10.1016/j. corsci.2009.02.009.

Mackay, A.L. (1960). B-Ferric oxyhydroxide. Mineral Mag. 32, $545-557$.

Morcillo, M., Feliu, S., Simancas, J. (1993). Deviation from bilogarithmic law for atmospheric corrosion of steel. Br. Corros. J. 28, 50-52 http://dx doi.org/10.1179/000705993798268278.

Morcillo, M., Almeida, E., Rosales, B., Uruchurtu, J., Marrocos, M. (1998). Corrosion y Protección de Metales en las Atmósferas de Iberoamérica. Parte I - Mapas de Iberoamérica de Corrosividad Atmosférica (Proyecto MICAT, XV.1/CYTED). CYTED, Madrid.

Morcillo, M., De la Fuente, D., Díaz, I., Cano, H. (2011). Atmospheric corrosion of mild steel. A review. Rev. Metal. 47 (5), 426-444. http://dx.doi.org/10.3989/revmetalm.1125.

Morcillo, M., Díaz, I., Chico, B., Cano, H., De la Fuente, D. (2014a). Wethearing steels: from empirical development to scientific desing. A review. Corros. Sci. 83, 6-31. http:// dx.doi.org/10.1016/j.corsci.2014.03.006.

Morcillo, M., Chico, B., Alcántara, J., Díaz, I., Simancas, J., De la Fuente, D. (2014b). Atmospheric corrosion of mild steel in chloride-rich environments. Questions to be answered. Mater. Corros. http://dx.doi.org/10.1002/maco.201407940.

Morcillo, M. Chico, B., Díaz, I. Cano, H. De la Fuente, D. (2013). Atmospheric corrosion data of weathering steels. A review. Corros. Sci. 77, 6-24. http://dx.doi.org/10.1016/j. corsci.2013.08.021.

Morcillo, M., González-Calbet, J.M., Jiménez, J.A., Díaz, I., Alcántara, J., Chico, B., Mazarío-Fernández, A., GómezHerrero, A., Llorente, I., De la Fuente, D. (2015). Environmental conditions for akaganeite formation in marine atmosphere mild steel corrosion products and its characterisation. Corrosion (in press). http://dx.doi.org/10.5006/ 1672 .

Murad, E., Johnston, J.H. (1987). Iron oxides and oxyhydroxides. Mössbauer Spectroscopy Applied to Inorganic Chemistry. Long, G.J. (Ed.), PlenumPress, New York, pp. 507-582.

Murata, T. (2000). Weathering steel, en: R. W. Revie (Ed.). Uhlig's Corrosion Handbook. J. Wiley \& Sons, New York, pp. 569-580.

Neff, D., Dillmann, P., Bellot-Gurlet, L., Beranger, G. (2005). Corrosion of iron archaeological artefacts in soil: characterisation of the corrosion system. Corros. Sci. 47 (2), 515-535. http://dx.doi.org/10.1016/j.corsci.2004.05.029.

Nippon Steel Corporation (2006). Coastal Weathering Steel $($ AC 330).

Nishimura, T., Katayama, H., Noda, K., Kodama, T. (2000). Electrochemical behavior of rust formed on carbon steel in a wet/dry environment containing chloride ions. Corrosion 56 (9), 935-941. http://dx.doi.org/10.5006/1.3280597.

Nomura, K., Tasaka, M., Ujihira, Y. (1988). Conversion electron Mössbauer spectrometric study of corrosion products of iron immersed in sodium chloride solution. Corrosion 44 (3), 131-135. http://dx.doi.org/10.5006/1.3583914.

Raman, A. (1988). Atmospheric corrosion problems with weathering steels in Lousiana bridges. Degradation of Metals in the Atmosphere, S.W. Dean and T. S. Lee (Ed.), ASTM STP 965, Philadelphia, pp. 16-29

Raman, A., Nasrazadani, S., Sharma, L. (1989). Morphology of rust phases formed on weathering steels in various laboratory corrosion test. Metallography 22 (1), 79-96. http:// dx.doi.org/10.1016/0026-0800(89)90024-4.

Raman, A. Nasrazadani, S., Sharma, L., Razvan, A. (1987). Morphology of rust phases formed on weathering steels during outdoor atmospheric exposure in sheltered locations under the bridges. Pract. Met. 24, 535-548.

Razvan, A., Raman, A. (1986). Morphology of rust phases formed on naturally weathered weathering steels in bridge spans. Pract. Met. 23, 223-236.

Rémazeilles, C., Refait, P. (2007). On the formation of $\beta-\mathrm{FeOOH}$ (akaganéite) in chloride-containing environments. Corros. Sci. 49 (2), 844-857. http://dx.doi.org/10.1016/j.corsci. 2006.06.003. 
Sagoe-Crentsil, K.K., Glasser, F.P. (1993). Constitution of green rust and its significance to the corrosion of steel in Portland cement. Corrosion 49 (6), 457-463. http://dx.doi. org/10.5006/1.3316072.

Selwyn, L.S., Sirois, P.J., Argyropoulos, V. (1999). The corrosion of excavated archaeological iron with details on weeping and akaganeite. Stud. Conserv. 44 (4), 217-232.

Shibata, T. (2014). Corrosion modelling of carbon steel, 19th International Corrosion Congress (ICC2014), The Corrosion Science Society of Korea, Jeju, Korea.

Shreir, L.L., Javman, R.A., Burstein, G.T. (1993). Corrosion, Publisher Butterworth-Heinemann, Oxford, p. 1146.

Ståhl, K., Nielsen, K., Jiang, J., Lebech, B., Hanson, J.C., Norby, P., Van Lanschot, J. (2003). On the akaganéite crystal structure, phase transformations and possible role in post-excavational corrosion of iron artifacts. Corros. Sci. 45 (11), 2563-2575. http://dx.doi.org/10.1016/S0010938X(03)00078-7.

Stratmann, M., Bohnenkamp, K., Engell, H. J. (1983). An electrochemical study of phase-transitions in rust layers. Corros. Sci. 23 (9), 969-985. http://dx.doi.org/10.1016/0010-938X (83)90024-0.

Tanaka, H., Mishima, R., Hatanaka, N., Ishikawa, T., Nakayama, T. (2014). Formation of magnetite rust particles by reacting iron powder with artificial $\alpha-, \beta$ - and $\gamma-\mathrm{FeOOH}$ in aqueous media. Corros. Sci. 78, 384-387. http://dx.doi.org/10.1016/j. corsci.2013.08.023.

Turgoose, S. (1982). Post-excavation changes in iron antiquities. Stud. Conserv. 27, 97-101. 